\title{
La ayuda mutua con fines domésticos: una forma de trabajo infantil a través de redes socio-familiares
}

\author{
Carmen María Sandoval Figueroa \\ Pontificia Universidad Católica del Perú
}

\author{
Fecha de recepción 18-07-2018 \\ Fecha de aceptación 21-09-2018
}

\section{RESUMEN}

El artículo aborda las formas de inserción de niñas y niños en el trabajo infantil doméstico a través de redes socio-familiares. El trabajo realizado por los menores es calificado por los actores como una suerte de ayuda mutua con fines domésticos, de manera que el menor apoya en quehaceres domésticos a un pariente o conocido. Tanto los menores como sus familiares basan estos intercambios en el sistema de ayuda mutua entre parientes y conocidos, la colocación del menor se da en base a la confianza entre los actores. Se presentan tres formas de inserción a través de cadenas socio familiares: (1) por proximidad afectiva y residencial, (2) por vínculos de parentesco por elección y (3) por vínculos de parentesco consanguíneo. La ayuda mutua con fines domésticos es una práctica que los niños realizan previamente a su inserción en el trabajo infantil doméstico realizado en familias de terceros.

PALABRAS CLAVE: Trabajo infantil, trabajo infantil doméstico,redes socio-familiares, vínculos sociales.

\section{Mutual help with domestic purposes: A form of child labour through socio-familial networks}

\begin{abstract}
This article deals with forms of children's inclusion in domestic child labour through their sociofamilial networks. These minors describe the work they perform as a kind of mutual help with domestic purposes, so that the minor supports a relative or acquaintance in domestic chores. Both children and their relatives base these exchanges on the system of mutual help between relatives and acquaintances, and the placement of the minor is based on trust between the actors. The article presents three forms of children inclusion in domestic child labour through socio-familial chains: (1) by affective and residential proximity, (2) by ties of kinship by choice, and (3) by consanguineous kinship ties. Mutual aid for domestic purposes is a practice that children perform prior to engaging in domestic child labour carried out for third-party families.
\end{abstract}

KEYWORDS: Child labour, domestic child labour, socio-familial networks, social ties. 


\section{Introducción}

L

a ayuda mutua con fines domésticos se da en el ámbito de las redes sociofamiliares, se trata de una práctica social aparentemente previa a la inserción de menores en el trabajo infantil doméstico realizado en hogares de terceros. Los jóvenes a los cuales tomamos testimonio narran haber vivido esta experiencia previamente a su inserción en servicio doméstico remunerado en hogares de terceros. La ayuda mutua con fines domésticos no puede ser entendida solamente como un tipo de trabajo infantil' ${ }^{1}$, sino como arreglos entre familiares que intercambian ayudas mutuas desiguales y que crean jerarquías entre parientes como resultado del trabajo realizado por los menores. La circulación de los niños entre varias familias hace parte de una red social y/o familiar con la finalidad de brindar ayuda exclusivamente en actividades relacionadas a los quehaceres domésticos. A diferencia de la práctica de la circulación infantil, los menores no son propiamente acompañantes sino más bien ayudantes. Generalmente es una práctica que se desarrolla de manera íntima, en un círculo de conocidos, de manera que el niño o la niña circula entre familias que son cercanas a su propia familia para brindar su apoyo en el ámbito del trabajo doméstico infantil. Las prácticas de la circulación infantil y del trabajo doméstico infantil están en estrecha relación, los límites que las separan son en ocasiones poco claros y difusos; sin embargo, se puede observar que se basan en relaciones jerárquicas y de servicios que entretejen los actores con el fin de brindarse ayuda mutua con fines domésticos. En este ensayo hemos dado énfasis en los modos de inserción de los menores en estas redes; de manera que, no presentamos las relaciones cotidianas que se establecen entre los menores y las personas que los acogen, las cuales generalmente están impregnadas de discriminación hacia las niñas y los niños, atravesadas además por tensiones de relaciones intergeneracionales y de género, reconocemos que los puntos mencionados son otro tema de estudio.

1 El trabajo infantil es entendido como una actividad económica que realiza un menor al seno de su familia o para terceros, por realizar este trabajo el menor recibe una retribución que se presenta en diversas formas (dinero, regalos, escolarización, favores). La OIT reconoce dos tipos de actividades en el marco del trabajo infantil actual; el modo "child work" hace referencia al trabajo que no es perjudicial ni dañino para el niño, no afecta su desarrollo, su salud ni su educación; y el modo "child labour" hace referencia al trabajo nocivo, a formas de esclavitud y servilismo. El servicio doméstico infantil está categorizado como una de las peores de trabajo infantil (OIT, 2004). Además, la OIT (2013) sostiene que la denominación para este tipo de servicio ofrecido por los niños es "trabajo doméstico infantil", se trata de una actividad realizada por niñas y niños para hogares de terceros o empleadores en el sector del trabajo doméstico. En lo que respecta a las niñas y niños que no cuentan con la edad mínima para realizar esta actividad este tipo de labor se denomina "trabajo infantil en el trabajo doméstico". Por otro lado, en cuanto al trabajo infantil, Invernizzi (2001: 15) afirma que se trata de una actividad social, la cual es producida por los actores a partir de las significaciones que ellos les pueden atribuir a sus prácticas, a su entorno y a sus acciones. De manera que es muy difícil categorizar el trabajo infantil de una sola manera dado que sus prácticas son múltiples. 


\section{Metodología}

Estudio comprensivo sobre las niños y niños trabajadores infantiles domésticos en Lima. Se realizaron observaciones en un barrio popular al sur de Lima. Las observaciones se llevaron a cabo en 2 espacios: en el comedor popular y la asociación de comerciantes del mercado más céntrico del barrio. Las observaciones se realizaron en 3 períodos de dos meses cada una. Además, se realizaron entrevistas jóvenes a trabajadoras y ex-trabajadoras del hogar que vivían en este barrio y que trabajaron cuando niños en servicio doméstico. Los informantes claves fueron mujeres asociadas al club de madres, comerciantes del mercado del barrio y dirigentes vecinales de la localidad.

\section{Modos de establecer cadenas de inserción con fines domésticos en redes socio-familiares}

A continuación presentaremos tres modos de inserción de niñas y los niños redes socio-familiares para brindar ayuda con fines domésticos: las cadenas establecidas por proximidad afectiva y residencial, las cadenas concertadas en base a vínculos de parentesco por elección y cadenas establecidas en base a vínculos de parentesco consanguíneo.

\section{Modo 1: Cadenas por proximidad afectiva y residencial}

La inserción de los niños en prácticas como la ayuda mutua con fines domésticos se vinculan estrechamente a la práctica de la circulación infantil en contextos locales. En el caso de la circulación infantil, encargar a un niño en una familia representa un acto solidario dentro de estas redes, tanto para la familia que deja ir al niño como para la familia que lo recibe. El acto solidario se sella porque la persona que recibe al niño es percibida como cercana o como un pariente (no necesariamente en referencia a un pariente con quien se tiene una filiación consanguínea sino también parientes por el trato cotidiano), del cual se percibe se encuentra en una situación o posición mejor con respecto a la familia que deja ir al niño. La colocación de un hijo representa también una estrategia o una oportunidad que los padres del menor perciben como una inversión o como una descarga en términos financieros, sean temporales o definitivos para la familia (Fonseca 1985). Las familias que optan por la circulación de sus hijos se encuentran mayoritariamente en un período de difi- 
cultad económica o en una situación de crisis familiar a la cual deben hacer frente temporalmente. En ocasiones, los niños pueden circular dentro del mismo barrio, y otras veces, se van a otros barrios o a otras ciudades. Las diferencias sociales y económicas entre las familias que dejan ir a los niños y las que los reciben no son siempre claras. Como explica Leinaweaver (2009), en el caso de la circulación infantil, el menor puede ser colocado en una familia o preparar su propia circulación e ir a vivir con una familia y acompañarlos. ${ }^{2}$

Por otro lado, la ayuda mutua con fines domésticos es aparentemente temporal en la vida del niño o del adolescente, es una práctica preliminar a la inserción de menores en servicio doméstico remunerado y encubre formas de trabajo infantil doméstico. Por esta razón es necesario estudiarla para comprender cómo se tejen las relaciones familiares para captar niños para el trabajo infantil doméstico. Este tipo de actividad no está exenta de devenir una forma de servidumbre, de explotación infantil o de trata de menores a la cual puede ser sometido el menor. Lo que es importante destacar es que los niños experimentan múltiples condiciones de vida el marco del trabajo infantil doméstico porque los límites entre las prácticas mencionadas dependen de múltiples factores como la edad del niño, el género, las condiciones de trabajo, los tratos, la exposición del niño al peligro, etc. A continuación presentaremos un caso para ilustrar cómo entran los niñas y niños en las redes socio-familiares que los insertan en el trabajo infantil doméstico.

El primer caso retrata la historia de Concepción ${ }^{3}$, una joven que comenzó a apoyar en tareas domésticas a su vecina del barrio cuando tenía 9 años. Concepción explica que el lugar de encuentro para realizar los tratos de ayuda en quehaceres domésticos se daba en el comedor popular de su barrio, durante el momento en que los vecinos se aproximaban para comprar o recoger el almuerzo ${ }^{4}$. Los tratos entre niños y adultos son familiares, se conocen y se tutean. Las relaciones interpersonales que se establecen en este lugar revelan afectividad, inclusive complicidad, relaciones de confianza, de intercambioy de compartir sentimientos comunes. Estas personas forman un círculo de conocidos bastante fuerte y denso por varias razones: son vecinos, frecuentan cotidianamente el comedor y son migrantes de provincia en Lima. El comedor es un lugar de sociabilidad permanente, los vecinos

2 Según la autora, esta situación no exime al menor de recibir malos tratos.

3 Entrevista realizada a Concepción en un comedor popular de Nuevo Lurín.

4 Se observó que entre las personas que se llevaban los recipientes a casa habían niñas y niños de todas las edades y adultos. Algunos de los menores eran parientes de las mujeres que cocinaban y otros las ayudan. Es la dinámica del comedor que todos hablen un poco entre ellos, los niños suelen dirigirse a hablar a las mujeres que están en la cocina, en ocasiones conversaban con los adultos u otros niños que estaban en la sala mientras esperaban que les sirvan o repartan la comida. Se pudo observar también que a diferencia de los adultos, los niños estaban en tránsito, no se quedaban en el lugar. 
se encuentran para hablar y es aquí donde se fortalecen las relaciones sociales entre ellos. Lo particular es que las relaciones intergeneracionales que establecen los actores permiten que se realicen conversaciones y acuerdos que desencadenan intercambios para que los niños ingresen al mundo del trabajo infantil doméstico.

En ocasiones, estos intercambios para ofrecer ayuda mutua de un menor para una familia pueden establecerse en menos de dos minutos. Las breves conversaciones son el inicio de transacciones que podrán tener lugar días después: la colocación de un menor, sobre todo niñas, como ayudante en trabajo doméstico en beneficio de una familia de la localidad. Esta transacción es particular dado que las lógicas que las subyacen son las de la ayuda mutua socio-familiar, apoyos que son comunes de observar entre migrantes de la provincia en Lima, además de formas de circulación infantil en el contexto de la familia, la amistad y la proximidad residencial en barrios populares. Cuando los actores hablan de ayudarse no están hablando de trabajo sino en términos de ayuda propiamente dicha: la transacción evocada por los actores muestra cómo se provoca el inicio del establecimiento de una solidaridad compartida entre gente que se conoce. El arreglo no es desinteresado: por una parte se solicita que el niño o la niña sea un apoyo en la realización de los quehaceres domésticos para una familia de terceros, en contraparte se ofrece un apoyo para la escolarización del menor u otro beneficio. Los actores se ayudan y para eso recurren a la activación de redes socio-familiares que se sustentan en la proximidad residencial, así como en la proximidad afectiva. A veces la gente se conoce, otras veces no, lo común es que recurren a la confianza para activar estas redes de intercambio para introducir niños en el trabajo infantil. Ocurre que en ocasiones las ayudas de los menores pueden ser recompensadas con propinas, esto puede interpretarse como un valor añadido que se les brinda por la ayuda. Cuando se trata de niños y niñas que realizan trabajo doméstico no se suele hablar en términos de salario sino de propina. Recordemos que las propinas son regalos de poco dinero y están inscritos en el marco de la intimidad, de la familiaridad y de la proximidad afectiva (Leinaweaver 2009: 154).

Veamos el caso de las relaciones que se establecen entre los actores que participan en las interacciones del comedor popular al acudía Concepción. Retomo la idea de que las breves conversaciones en este lugar pueden ser el inicio de transacciones que podrán tener lugar días después: la colocación de un menor, sobre todo niñas, como ayudante de una familia. Una mujer adulta —Delfina - y niña menor de 10 años - Concepción - van a establecer un diálogo que las llevará a crear un trato que podría interpretarse como una ayuda mutua con fines domésticos. La negociación se realiza en el espacio del comedor mientras los menús son servidos. Las 
conversaciones que se establecen entre ellas las llevan a negociar a pesar de las diferencias de edad, así se tomará el acuerdo de que Concepción ayude en la casa de Delfina. La palabra trabajo doméstico no es mencionada en estas interacciones. Las preguntas que nos cuestionan son las siguientes: ¿la relación que establecen Delfina y Concepción podría ser considerada como una forma de ayuda mutua entre conocidos? ¿La transacción que ellas establecen puede revelarnos una relación de trabajo infantil?

A fin de responder las interrogantes veamos primero la relación entre Delfina y Concepción, ambas aparentan tener una relación antigua, se saludan y se conversan. La cercanía entre ambas se aprecia en trato que se dan. "[Delfina] ¡Concepción! ¡Qué bueno verte! ¿Qué es de tu vida? ¿Dónde andabas? Te venía a ver para ver si puedes venir a ayudarme ${ }^{\prime \prime 5}$ Ellas se conocen previamente, aparentemente se han dejado de ver por un tiempo. Ese encuentro no es pasajero porque va tener incidencias en la vida de las dos mujeres. Para Delfina, volver a ver a Concepción es una oportunidad para concretar la activación de la ayuda mutua con fines domésticos, una ayuda que estaba buscando, dado que invita a la niña a activar la ayuda mutua solicitando que la apoye en su casa. La intención de Delfina paraarreglar un trato en ese instante es evidente. Sin embargo, el trato va tardar en hacerse efectivo porque Delfina estará obligada de establecer un acuerdo previo con los padres de Concepción, lo que significa un arreglo familiar con fines de ayuda mutua. Esta forma de establecer cadenas para la ayuda mutua con fines domésticos es la puerta de entrada del niño al trabajo infantil doméstico.

En el trato de Delfina y Concepción se habla en términos de ayuda y no de trabajo doméstico. Para los actores, la diferencia entre el trabajo y la ayuda reside en el hecho de la circulación de la niña, por esta razón consideran sus intercambios como una forma de ayuda mutua entre conocidos. Ambas familias se vinculan para ayudarse y harán circular los apoyos, los van a intercambiar recíprocamente, o al menos, en lo que ellos consideran como recíproco e igual. La ayuda tiene un vínculo con la confianza compartida, no se pide ayuda de quienes se desconfía. Los adultos median las formas de ayuda y establecen los términos del arreglo. Se observa que Delfina inscribe su pedido de ayuda en el marco de las solidaridades y los intercambios entre miembros de una localidad. A pesar de esta proximidad afectiva y residencial, la demanda de ayuda con fines domésticos revela un intercambio desigual y asimétrico por las diferencias de edad entre los actores, por la naturaleza de las actividades que realizará cada actor y por el tipo de retribución

5 Registro de observaciones. 
que recibirá cada uno. La niña está realizando una forma de trabajo infantil encubierto en ayudas que se dan entre personas que tienen relaciones socio-familiares.

La ayuda mutua con fines domésticos se activa a consecuencia de solidaridades compartidas en el seno de un grupo social, entre individuos que pertenecen a clases sociales parecidas o diferentes, o entre aquellos que comparten tradiciones culturales, al seno de redes familiares o sociales (amigos, conocidos, vecinos, etc.). Entendemos, entonces, que la ayuda con fines domésticos no es un intercambio de servicios simple sino más bien complejo, que involucra múltiples actores y escenarios; pero que tiene en común el intercambio de solidaridades compartidas de manera asimétrica entre las partes que dan como resultado una forma de encubrir el trabajo infantil. La ayuda mutua es un sistema que se activa con objetivos precisos que identifican los actores, reconocen que lo que circula en esta práctica son ayudas, solidaridades y reciprocidades materiales y afectivas. Se reconoce una utilidad material inmediata (ayudar a alguien en una situación de dificultad inminente); pero también, puede entenderse como un proceso que sirve para perennizar las relaciones entre actores, garantizando la recuperación de una inversión realizada (Petite 2005: 18). La ayuda mutua va permitir entrelazar las reciprocidades entre gente que se conoce; sin embargo, las reciprocidades resultado de ese intercambio no son idénticas ni consideradas de la misma manera por los actores.

Si bien las ayudas y las solidaridades que circulan en el marco de la ayuda mutua pueden efectuarse de manera armoniosa y recíproca, en ocasiones también se pueden generar tensiones o conflictos que impactan las relaciones que establecen las personas implicadas en estos intercambios. Entonces, la ayuda mutua puede servir para fortalecer los vínculos entre los actores que participan en esta relación, así como hacer las relaciones más densas y complejas, inclusive en detrimento de la relación. En síntesis, la ayuda mutua tiene un componente relacional pero también utilitario, dado que es una respuesta a una demanda de ayuda concreta. La ayuda mutua puede efectuarse entre individuos que comparten un vínculo de parentesco a varios niveles: consanguíneo, ritual, cotidiano, por alianzas; pero también entre individuos que no comparten vínculos de parentesco pero que son cercanos porque han establecido relaciones en común: vecinos, colegas, amigos (Petite 2005). Bidart, Degenne y Grossetti (2011) señalan que la ayuda mutua es un evento complejo que depende no solamente de situaciones individuales 0 particulares donde ella tendrá lugar, sino también de situaciones y sentimientos particulares de los actores, además de la calidad de las relaciones constituidas. Vemos entonces que la confianza no solo representa un elemento que va iniciar la ayuda mutua, sino que también va ser indispensable para mantenerla. En este 
sentido, para confiar un niño o una niña a una familia en el marco de la ayuda mutua, la confianza es el elemento desencadenante para la inserción del menor en el trabajo infantil doméstico, pero también es un elemento que la familia del menor valora porque busca el buen trato, condición que no siempre se puede garantizar.

En el caso de la ayuda mutua con fines domésticos, las ayudas y los intercambios son de naturaleza diferente. No se intercambia "ayuda por ayuda" en todos los casos, sino que por la ayuda que brinda el menor en una casa recibirá una retribución "otra" diferente a la ayuda propiamente dicha. Generalmente, las formas de retribuir las ayudas realizadas por menores a una familia de conocidos, en el marco de actividades asociadas a tareas domésticas, pueden ser la escolarización, apoyo en tareas escolares, o eventualmente, propinas. Además, otros aspectos sustentan este tipo de relaciones asociadas a la ayuda mutua con fines domésticos. Por ejemplo, el prestigio que puede adquirir la familia que recibe un niño por ayudarloen su escolarización, es prestigioso a la vista de los vecinos, dado que la familia receptora tiene los recursos educativos, sociales y/o económicos para recibir al menor. No siempre la familia receptora interpreta que, recibir a un niño en el marco de la ayuda con fines domésticos, es una fuente de desprestigio. Las diferencias en el estatus social de los vecinos (representantes de organizaciones populares o dirigentes, comerciantes, profesionales, etc.) determinan cierto tipo de relaciones de poder y de relaciones de dependencia que impactan la dinámica de la ayuda mutua con fines domésticos: un vecino que desea colocar a su hijo o hija para activar una ayuda mutua con fines domésticos buscará una familia que pueda garantizar la reciprocidad de la ayuda (Sandoval 2015). ${ }^{6}$

Otro factor de diferenciación es la edad de los actores. Las relaciones intergeneracionales son puestas a prueba en este tipo de intercambio, ¿hasta dónde puede decidir un niño o niña la activación de una red para la ayuda mutua con fines domésticos? El rol de los niños aparenta ser activo en algunas negociaciones, pero la decisión es tomada por la familia, sobre todo por la madre. El género de los actores es también un factor de diferenciación. En el caso que mencionamos -Delfina y Concepción - las ayudas circulan entre las mujeres, pero no siempre es estrictamente así, como veremos más adelante. Si analizamos la prioridad entre las diferencias de género y edad veremos que lo que prima es el género porque las ayudas mutuas con fines domésticos circulan sobre todo en la línea de las mujeres (Petite, 2005). En la ayuda mutua con fines domésticos, el indicador de que existe

6 Por ejemplo, una familia de dirigentes del barrio o de profesores tendrá más reticencias para activar una red de ayuda mutua con fines domésticos, probablemente sea, por su perfil social, la familia receptora. La familia receptora debe asegurar no solamente recursos financieros sino sobre todo sociales. 
una forma de trabajo infantil lo constituye el valor de la propina. Leinaveawer (2009) afirma quela propina es un elemento que se utiliza para producir y poner en evidencia diferencias y jerarquías sociales entre los actores, "la persona joven, al aceptar una propina, está reafirmándole a quien se la da que esta persona retiene una superioridad social y un control."(p.160). Se justifican asílas desigualdades entre actores en un espacio social. En el contexto del trabajo infantil la palabra "salario" no es funcional porque no se utiliza corrientemente, la propina deviene entonces un término más preciso para analizar este tipo de intercambio donde media dinero.

\section{Modo 2: Cadenas en base a vínculos de parentesco por elección}

Otra forma en que los niños circulan en redes socio-familiares en el marco de la ayuda mutua con fines domésticos está basada en el parentesco ritual o cotidiano: "el fundamento social del parentesco andino es el principio básico de las relaciones de circulación infantil así como para la mayoría del servicio doméstico"(Leinaweaver 2009: 173). Nuestra intención no es analizar aquí cómo se construyen los vínculos del parentesco ritual, sino más bien ilustrar cómo se utilizan con el fin de activar la ayuda mutua con fines domésticos entre parientes, lo cual involucra relaciones de trabajo entre niños y adultos de un grupo familiar. Es necesario precisar que la colocación de niños no se realiza explícitamente entre actores que comparten un vínculo de parentesco ritual directo sino también indirecto, de manera que las redes por donde circulan los niños se amplían. Para poder comprender cómo ingresan los niños a las redes de ayuda mutua con fines domésticos es necesario contextualizar estos desplazamientos en el marco de la migración interna, tanto a nivel de los intercambios entre migrantes como entre migrantes y limeños.

Vamos a repasar rápidamente algunas nociones sobre parentesco que nos van aayudar a comprender los casos que presentaré más adelante. El parentesco ritual es un parentesco por elección; así, generalmente se crean relaciones familiares entre individuos que no están emparentados por vínculos consanguíneos o por alianzas matrimoniales. Pero también existe la posibilidad que una familia con vínculos de parentesco ya establecidos decida reforzar sus lazos sirviéndose del parentesco ritual. Las filiaciones que son resultado de este parentesco por elección están sostenidas por vínculos espirituales. Los vínculos de parentesco consanguíneo o por elección están íntimamente ligados uno a otro en las sociedades occidentales. El

7 El parentesco ritual relaciona individuos de manera directa o indirecta. Serán parientes directos aquellos individuos que han participado en una alianza (bautismo, matrimonio, etc.) y tendrán vínculo indirecto los parientes de los individuos que sellaron la alianza. 
padrinazgo y el compadrazgo son tipos de filiación electiva. El vínculo espiritual que se establece puede ser "intensivo" o "extensivo" dependiendo de las funciones que cumple al seno del parentesco. Puede calificarse de intensivo cuando sirve para intensificar un vínculo ya existente; por ejemplo, cuando se escoge de padrino de un hijo a un hermano. Puede calificarse de extensivo cuando se escoge para el padrinazgo a un amigo de infancia o a un vecino (Fine 1997: 162). Así la efectividad del padrinazgo y del compadrazgo es que permite crear amistad entre parientes consanguíneos y, asimismo, permite crear parentesco entre amigos.

En el caso del parentesco ritual como lo conocemos y lo estudiamos en nuestro país, él está prioritariamente focalizado en los estudios de parentesco andino ritual característico de las zonas rurales y de las migraciones del interior del país hacia Lima. El parentesco es un vínculo que los actores emplean para activar la ayuda mutua, la migración, inclusive subyacen prácticas como el trabajo infantil. Rutte García (1976) deslizaba la imagen de la joven provinciana que era entregada a sus padrinos limeños para que la cuiden y de paso les ayudaba con las tareas de la casa. Esta figura, muy conocida y evocada en diversos estudios sobre trabajo doméstico juvenil y adulto, es la más representativa para describir vínculos entre el parentesco ritual y el servicio doméstico. Escalante (2002: .29) explica que el parentesco asociado al trabajo doméstico es utilizado por los actores como forma de socialización. Para el adulto significa extender su círculo de parentesco, vinculando lo rural a la ciudad, lo que provoca extender sus redes socio-familiares. Para la niña o adolescente significa conocer otro mundo y socializarse con otra familia para adquirir otras costumbres más citadinas. No necesariamente en un traslado que represente salir de una zona rural hasta Lima, sino también en circulaciones más pequeñas, en un diálogo campo-ciudad permanente y próximo.

A continuación presentamos casos de un niño y una niña que brindaron ayuda con fines domésticos a personas con algún vínculo de parentesco ritual con sus familias. El primer caso es el de Pascal, un joven que cuenta haber comenzado a trabajar a los 6 años vendiendo golosinas en la calle y luego haber salido de la calle para trabajar en una casa ${ }^{8}$. Los primeros años Pascal vendía golosinas al costado de una ambulante del mercado de su barrio, pero después comenzó a recorrer las calles y subir a los buses con el fin de vender sus productos. Cuando tenía 10 años fue asaltado y su padre decidió ponerle fin a esta actividad y lo llevó a trabajar como ayudante en una casa donde él ofrecía servicios de limpieza. Pascal refiere también que a sus padres no les gustaba que él estuviera mucho tiempo en la calle porque

8 Entrevista a Pascal, un joven que trabajaba en limpieza para una familia en el distrito de San Isidro. 
jugaba con otros niños, faltaba al colegio y se distraía, calificando a los amigos de Pascal como "malas juntas".

El padre de Pascal limpiaba casas para familias de clase media y en algunos locales. En un inicio, Pascal ayudaba a su padre durante los fines de semana, los otros días asistía al colegio y ayudaba en su casa. Pero a medida que transcurrió el tiempo las ayudas en casa de terceros se volvieron más regulares y él intuía que su padre tenía intenciones de introducirlo al trabajo infantil doméstico:"me sorprendía que de pronto [él] me ayudara y que me llevara a su trabajo. Me preguntaba siempre ¿qué quería? Era muy extraño que me estuviera llevando." A los 12 años, una vez que termina la primaria, Pascal va circular a la casa del compadre de su padre para ayudar a esa familia con las tareas domésticas y estudiar la secundaria en otro colegio. Lo que estaba realizando el padre de Pascal era una preparación para que su hijo pudiera asumir esas tareas domésticas, una preparación de la que Pascal no tenía conocimiento y que descubrió intuitivamente meses después.

Pascal refiere que su padre lo formaba para dejarle esa herencia. Era una formación para el trabajo que estaba inscrita en el marco familiar e íntimo:"[El padre decía] Quisiera que al menos aprendas esto. Si me muero ya tienes esto, te dejo con tu padrino para que le ayudes, ya tú vas a saber hacer bien. Vas a tener tu colegio pero también tu trabajo". Algunas propinas le llegaban de manera irregular, a veces su padre le daba algo de dinero y otras veces eran las familias a las que ayudaba: "comencé ayudando, limpiaba ventanas, los baños, algo fácil. Después ya he comenzado a limpiar la terraza, la sala, eso era más fuerte. A veces recibía mi propina, mi papá también me daba algo. Trabajando todo el día sacaba muy poco, lo bueno era que no gastaba nada porque mi papá me llevaba y me traía." Las ganancias de Pascal eran menores que cuando trabajaba en la calle y además eran irregulares, pero en revancha solo ayudaba a su padre los fines de semana. Pascal estaba realizando una actividad previa a su inserción en el mundo del trabajo infantil doméstico en el marco de las redes familiares.

Pascal se muda a vivir con el compadre de su padre durante un año. El acuerdo es que Pascal ayudará esta familia el tiempo que dura el año escolar. Se trata de una mejor escuela, en un barrio de clase media, lo que convence a Pascal para realizar este cambio y realizar este tipo de trabajo infantil. Al inicio Pascal es reticente y decide enfrentarse a sus padres, se angustia porque se alejará de sus amigos y de su familia; sin embargo, él no tiene elección, la transferencia ha sido impuesta por su padre y él la acepta. Poco a poco, Pascal se da cuenta de la estrategia de su padre para sacarlo del trabajo de calle y llevarlo a ayudar a una familia bajo la figura de la ayuda mutua con fines domésticos. El arreglo no es claro porque Pascal no tiene 
definido lo que hará. Ayudar es hacer todo y a la vez hacer nada, es una palabra ambigua que escapa a los límites de una actividad. Para Pascal la preocupación residía en conocer exactamente las actividades que debía realizar y si recibiría o no una propina. Su padre se ocupó de cambiarlo de colegio y de dejarlo con su compadre, después delega la responsabilidad del cuidado de Pascal al familiar y se ausenta. Pascal acepta con resignación la transferencia porque su padre termina por convencerlo, le dice que el trabajo en la calle se acabará porque ya está "crecido": "ya no vas a poder seguir subiendo a los carros, ya no te comprarán nada —-me decía—, más les compran a los chiquitos bebitos."También lo convenció diciéndole que le podían volver a robar o no dejar subir a los buses. Al escuchar estos argumentos Pascal cesa de oponerse a la circulación impuesta.

Veamos ahora los vínculos de parentesco que tenían el padre de Pascal y la familia que lo acogió. Favio - el compadre - era padrino de bautizo de una de las hermanas de Pascal. Muchos años antes el padre de Pascal trabajaba limpiando la casa de Favio, pero dejó de hacerlo cuando se volvieron compadres. Sin embargo, él continuaba trabajando para los vecinos de Favio o la gente que lo conocía porque lo recomendaba y vinculaba con sus conocidos. Favio era médico, tenía un consultorio al costado de su casa, Pascal comenzó limpiando este espacio. Como afirma Leinaweaver (2009), es común ver a menores realizando pequeños trabajos para las familias de substitución. La circulación fue arreglada entre adultos con el fin de que él tuviera mejores oportunidades de estudio, pero la ayuda brindada por la familia de substitución no era gratuita porque en retribución Pascal debía realizar algunas actividades que pueden calificarse como trabajo infantil doméstico.

En este caso se observa que las relaciones de compadrazgo que subyacen las relaciones de ayuda mutua son de tipo vertical y asimétrico. Pascal realiza un tipo de circulación en el contexto de la proximidad afectiva entre adultos que son familiares por el parentesco ritual. Además, la circulación se realiza en el marco de una alianza por compadrazgo entre individuos de clases socioeconómicas diferentes. Como hemos visto, las desigualdades entre estas familias hacen que los intercambios sean verticales y no equivalentes, de lo cual se puede inferir que la ayuda mutua con fines domésticos se genera a partir de relaciones de ayuda mutua asimétricas y desiguales, finalmente el menor termina realizando un tipo de trabajo infantil doméstico. Si bien las relaciones pueden cambiar un poco luego de que los actores realizan una alianza ritual que los hará parientes, la disolución de diferencias y jerarquías no es real, sino más bien una ilusión del vínculo de parentesco. Para los actores, la relación será diferente porque hay presentes marcadores de diferencia de clase y de pertenencia étnica, así como de categorías profesionales, que 
subyacen la relación, que están presentes en sus intercambios y en sus relaciones cotidianas. ${ }^{9}$ Lo que es particular en las relaciones de compadrazgo en el marco de la ayuda mutua con fines domésticos es que el vínculo de parentesco va acercar a los actores a pesar de sus diferencias. Dos hombres en una relación jerarquizada, que en otro contexto no podrían establecer una relación amical o familiar, van a aproximarse por el vínculo de parentesco y por la necesidad de ayudarse, el trabajo infantil doméstico es la actividad vinculante.

¿Por qué el caso de Pascal puede ser interpretado como un caso de circulación infantil en el marco de la ayuda mutua con fines domésticos? Los rasgos del intercambio nos hacen inferir que se trata de un tipo de circulación infantil, el padre de Pascal delega a su compadre la responsabilidad parental de su hijo, una responsabilidad tiene como característica una carga afectiva en las relaciones que entretejen los actores. La circulación se realiza en un contexto de transferencia informal y de común acuerdo basándose en lazos de confianza que son parte de vínculos de parentesco ritual. La colocación de Pascal en casa de Favio se efectúa gracias a la proximidad afectiva entre los actores, la cual tiene como base vínculos de parentesco, pero se trata de una forma de inserción en el trabajo infantil doméstico. La relación no es simple ni armoniosa, dado que la proximidad afectiva es influida por distancias socioeconómicas que separan a los actores, los roles se definen bien: quien da y quien recibe, teniendo cada actor un rol y un estatus en una jerarquía socio-familiar.

Presentaré a continuación otro caso de ayuda mutua con fines domésticos relacionada a vínculos de parentesco ritual. Basilia es una joven que cuenta haber ayudado en casa desde que tenía 8 años. Los primeros años de su vida vivió en una carencia material y emocional, sobre todo afectiva porque su padre la alejó de su madre cuando tenía 3 años. Basilia explica que su padre se mudó a vivir con ella a otro pueblo y se casó de nuevo, lo que reconstituyó su familia y cambió las relaciones familiares entre ellos: "Mi papá me llevó de la casa de mi mamá porque no tenía economía para mantenerme. Me llevó donde mi madrastra, allí comenzaron mis calvarios porque ella solo me trataba mal, era un diablo".10 Basilia explica que su madrastra la obligaba a realizar quehaceres domésticos, principalmente cuidar a sus medios hermanos cuando eran bebés. Por esta razón, Basilia se quedaba encerrada en casa durante todo el día y no asistía al colegio. Además, no podía salir a la calle y no participaba de las salidas familiares. La señora también despreciaba a

9 Por ejemplo, en nuestras conversaciones, Pascal se refería a su padre en términos de provinciano pobre y a Favio en términos de blanco rico o pituco.

10 Los testimonios fueron recogidos en las entrevistas a Basilia. 
Basilia y le daba malos tratos en ausencia de su esposo:"en realidad mis sufrimientos fueron muy fuertes cuando fui su entenada, me trataba peor que una empleada. Yo había estado con mi madrina cuando ella le obligó a buscarme, a mi papá. Me buscaba por su interés, yo era su muchacha gratis." El padre de Basilia no reconocía los sufrimientos de su hija, no la inscribía en el colegio y toleraba las relaciones que tenían su hija y su esposa. Basilia sufría una sobrecarga física y psíquica de trabajo, no tenía los mismos derechos de sus medios hermanos y estaba alejada de sus familiares más cercanos. El trabajo infantil doméstico es descrito por ella con la frase "ser una muchacha gratis" porque el trabajo que un niño realiza en el ámbito familiar es muchas veces gratuito.

Sobre el trato cotidiano Basilia explica:

[Ella] no me dejaba salir, estaba presa. Solo salía a comprar pan. Me quedaba mirar por la ventana, de allí le conversaba a mi madrina. Felizmente mi papá si me dejaba verla a mi madrina, yo iba a verla pero regresaba rápido porque tenía que atenderlo a mis hermanitos. Mi madrina me conversaba, me daba de comer, a ella nomás le contaba que quería irme de esa casa. Le pedí irme con ella pero no me aceptó. Ella sufría viéndome así. Un día me ha dicho: — ven a mi casa, vamos a esconderte, vamos a ver si tu papá te extraña y viene a buscarte-. Así me fui a esconderme con mi madrina, en secreto me he ido un tiempo.

Basilia y su madrina tenían un contacto cercano, sus encuentros duraban poco tiempo pero eran frecuentes. Fue durante esas visitas que Basilia convenció a su madrina para que la ayude a huir. Basilia, pudo de esta manera, preparar su propia circulación y partir de la casa de su padre cuando apenas tenía 10 años para insertarse en el trabajo infantil doméstico. Basilia explica la situación precaria en la que vivía su madrina porque era cuidadora de una casa y ganaba poco dinero destinado exclusivamente para la sobrevivencia de su familia. La madrina era una mujer sola, pero a pesar de que tenía varios hijos recibía a Basilia y la alimentaba. Basilia apreciaba el esfuerzo de su madrina porque era acogida en una familia que pasaba por una situación económica muy difícil:

De verdad que ella no tenía para darme nada, solo se quedaba conmigo para ayudarme. Tenía sus hijos y yo era una carga más para ella. Me ha inscrito a la nocturna, pero lo he dejado porque mi papá me vino a recoger y he tenido que salir. Cuando me he vuelto a mi casa ya no podía ir al colegio. Mi madrina trataba de ayudarme pero mi papá no le aceptaba. Él seguía diciendo que yo era una engreída y mal educada. Andaba diciendo que si le pedía permiso me hubiera dejado ir a vivir con mi madrina, pero no creo. Después ya, por pena ya se ha puesto de acuerdo con 
mi madrina y pude regresar al colegio, ese año terminé. Yo he regresado corriendo donde mi madrina, después ella lo ha convencido a mi papá para que me quede con ella. Yo me he quedado contenta con ella.

Basilia explica que viviendo en casa de su madrina también ayudaba en los quehaceres domésticos, esta actividad puede ser calificada como un tipo de trabajo infantil doméstico. Con respecto a los tratos cotidianos, Basilia explica que era bien tratada por su madrina y por los hijos de ésta: "allá hacía un poco de todo. [Ella] me trataba como su hija, sus hijitos eran como mis hermanos. Cuando tenía que ayudarle, yo le decía — ¿Te ayudo? ¿Necesitas algo? —. Así era. Todos le ayudábamos porque era buena, casi iguales hacíamos. Como yo era chica todavía ella me iba indicando lo que tenía que hacer. Le ayudaba pelando las papas, cosas así simples." La descripción realizada por Basilia ilustra el trabajo infantil doméstico que ella realizaba en casa de su madrina.

Cuando Basilia tiene 12 años, su madrina aprovecha la visita del tío de Basilia para proponerle que la lleve consigo, el hombre es hermano del padre de Basilia. Intervienen en el acuerdo únicamente la madrina y el tío de Basilia. Es en ese contexto que se produce el viaje de Basilia, ella llega a un pueblo y se queda solo unos días porque sufre una serie de maltratos y abusos, trabaja para la familia de su tío en largas jornadas, ayuda en la chacra y con los animales. En esas circunstancias Basilia decide fugar nuevamente y se pone en contacto con familiares que tiene en Lima, no regresa a su pueblo porque está avergonzada con su madrina. En Lima, Basilia vende caramelos y asiste a la escuela nocturna, en ese contexto conoce a su profesora y decide irse a vivir y se inserta en el trabajo infantil doméstico:

No quería regresar a la Sierra. Había pensado regresar a donde mi madrina, mi vida era muy triste pero no iba a volver, no quería verlos a ellos. Mi familiar me ayudó en Lima y me vine, agarré plata de mi tío porque tenía que pagar mi pasaje, con eso pagué mi pasaje. Después he vendido caramelos y estaba yendo a la nocturna. Estudiando primaria conocí a mi madrina, ella era mi profesora, con ella me quedé.

Si se analizan las relaciones familiares que dieron lugar a la inserción de Basilia en las redes de ayuda mutua con fines domésticos podemos observar que la relación de compadrazgo, entre el padre y la madrina de Basilia, aparenta ser horizontal: fue establecida entre individuos que comparten una proximidad residencial, que pertenecen al mismo grupo social y que cuentan con recursos financieros similares. Ambos establecen relaciones de respeto mutuo, a pesar de que esta relación se resquebraja con la huída de Basilia, los vínculos familiares se mantienen luego 
de manera durable. El padre de Basilia confía su hija a la madrina y la niña realiza actividades que pueden calificarse como trabajo infantil doméstico. Escalante (2002: 31) explica que las relaciones de padrinazgo y madrinazgo en la sierra están arraigadas en base al respeto mutuo entre padrinos y ahijados. Desde pequeños los niños aprenden a respetar a sus padrinos, dado que son considerados como padres espirituales y pasan algunas temporadas con la familia de sus padrinos con el fin de educarse y aprender algunas actividades. La autora afirma que el respeto de los ahijados se afirma porque tienen confianza en sus padrinos, condición que suele mejorar con la coresidencia y los buenos tratos en el compartir cotidiano. El respeto hacia los padrinos puede ser más fuerte cuando los niños son pequeños porque está mezclado con el afecto y el apoyo que los padrinos les pueden brindar. En ocasiones, la relación de respeto y confianza que construye un niño con sus padrinos puede ser más fuerte que la que construye con sus padres. También existen relaciones menos afectuosas e intensas, en ese caso el menor experimenta algunos malos tratos. Lo que es importante destacar en el caso de la ayuda mutua con fines domésticos es que la relación que se establece entre padrinos y ahijados se puede reafirmar como consecuencia a la coresidencia característica de esta práctica; sin embargo, esta actividad no deja de constituirse como una forma de trabajo infantil doméstico.

\section{Modo 3: Por vínculos de parentesco consanguíneo}

A continuación ilustraremos el caso de la ayuda mutua con fines domésticos entre parientes consanguíneos. Este tipo de circulación es otra puerta de entrada hacia el trabajo infantil doméstico. Rosalba muestra la ayuda mutua con fines domésticos entre miembros de una familia consanguínea a través de la migración. Rosalba, con 13 años de edad, tenía la intención de efectuar una migración a Lima y para lograrlo activó sus vínculos familiares con miembros de su familia que residían en Lima desde hacía más de 10 años. El objetivo de Rosalba fue asegurar su traslado, vivienda y un pequeño empleo en la ciudad. Sin embargo, sus planes se vieron alterados y para poder activar la ayuda mutua con fines domésticos debió llegar a un acuerdo con uno de sus tíos que se encontraba de visita en Celendín. Rosalba le pide que la lleve a Lima para trabajar en servicio doméstico. Le hace la propuesta de frente, su intención era trabajar en una casa para poder apoyar económicamente a sus padres y a sus hermanos: "en mi casa nos faltaba muchas cosas. Ya no soportaba cuando veía a mi mamá mal, necesitaba plata, tenía que ayudarla. Eso ha sido así, 
de un día para el otro, que me vine a Lima".11 Rosalba considera tener la edad para poder trabajar en servicio doméstico porque algunas de sus primas adolescentes se encontraban trabajando en casa, así que ella suponía que la colocación sería fácil. Una de sus primas le promete un empleo, pero le sugiere conseguir el permiso de su tío, asegurando así que su familia limeña la cuide durante su estadía en Lima. El tío de Rosalba acepta llevarla a Lima, pero una vez que llegan a la capital, Rosalba no consigue la colocación que esperaba y se ve obligada a apoyar con los quehaceres domésticos en casa de su tío. De esa manera Rosalba ingresa a trabajar en el trabajo doméstico infantil en redes familiares.

Rosalba aprovecha su estadía en Lima para inscribirse en el colegio y su tío se compromete a apoyarla. Para la familia de Rosalba se trata de la activación de la ayuda mutua familiar porque la niña puede quedarse a vivir con sus tíos al no encontrar trabajo en servicio doméstico. Para la familia del tío la interpretación que le dan a la ayuda mutua es diferente: reciben a Rosalba en su casa y la niña se compromete a realizar ciertas actividades relacionadas al trabajo doméstico, sobre todo en lo que se refiere a la ayuda en la limpieza y en las compras. La familia del tío de la niña es extensa, en una sola casa se concentran tres familias, cada una de ellas ocupa un piso. Rosalba explica que el acuerdo es solo cumplido por su tío, sus primas y su tía no la tratan como un familiar acogido sino como una empleada doméstica. Rosalba ayuda pero no recibe propinas: "le dije a mi tío si me podía dar algo por quedarme allí con ellos, él me dijo que solo podía darme mis estudios, me repetía que estaba dando mucho dejándome quedar allí en su casa. -Tienes que comprender-, me decía haciéndome callar". Los acuerdos sobre los tipos de ayuda que debe dar Rosalba no son claramente establecidos, ella tiene que organizarse para cumplir todas las actividades fuera del horario escolar. Las relaciones familiares con su tío son agradables, él la trataba como pariente (de manera afectuosa) y recordaba siempre los lazos familiares que tenían. Sin embargo, su tía era un poco más seria y menos afectuosa, pero para Rosalba los tratos eran buenos. Diferente era el caso de sus primas, quienes la trataban como si fuera una empleada doméstica:"mi tío me quería como su familiar, me trataba como tío, pero sus hijas eran odiosas, me trataban como su muchacha. Yo vivía con mi tío pero de día tenía que ir a verlas a mis primas".

Desde el inicio de su estadía en Lima, Rosalba reconoce que tiene dificultades para establecer una relación familiar con sus primas y no llega a tener vínculos fuertes con ellas. Rosalba percibía las actividades que realizaba eran intensas y con poco reposo, se veía enfrentada a una importante sobrecarga de trabajo, sobre todo

11 Los testimonios fueron recogidos en las entrevistas realizadas a Rosalba. 
cuando ayudaba a la familia de su prima que tenía niños pequeños. En cambio, cuando ayudaba a sus primas solteras, las actividades domésticas eran más ligeras. En ambos casos, Rosalba realizaba un trabajo infantil doméstico que era encubierto en forma de ayuda mutua entre familiares:

Cuando me he quedado en su casa de ellos era porque no tenía otra salida. Recuerdo que ayudarlo no me gustaba, me quedé por mi tío pero me daba rabia que no me pagaran. Extrañaba a mis papás, quería abrazarles, conversarles pero no podía. Encima no podía ayudarlos con la plata y no tenía para comprarle un medicamento a mi madre. Mi tío paraba repitiendo que lo ayudaba a mi papá porque me tenía en su casa, pero para mí eso no significaba nada de nada, me llegaba. No pude aprovechar nada ese año, mi papá me repetía que tenía que aprovechar mi colegio, que ya se iba a pasar rápido el tiempo. Cuando le decía que quería volver él no quería. Mi papá me decía que tenía que respetarlo a mi tío, por eso nomás me quedé.

Rosalba sostiene que su intención fue trabajar en servicio doméstico y no ayudar: "yo quería ganar plata, ¿no? Mi mamá estaba esperando la plata, ellas sabían eso, un poco de plata podrían haberme dado para enviar a mi casa. De frente me hubieran propuesto trabajo, nada hubiera pasado, con gusto lo aceptaba trabajar. No hicieron eso". En este caso, para Rosalba conservar los vínculos de parentesco con esta familia no es lo más importante, ella desea reemplazar la ayuda mutua con fines domésticos en una relación de servicio doméstico; así la relación entre los actores se transforma en una relación de servicio que tendrá como característica que empleador y empleado(a) son parientes directos.

Para los actores, la relación que Rosalba establece con la familia de su tío no es una relación estrictamente laboral sino más bien familiar, la cual se activó a partir de vínculos de parentesco directo y con la finalidad de brindarse ayuda mutua en el marco familiar y los actores la reconocen como tal. Se habla en términos de ayuda mutua con fines domésticos porque es un tipo de ayuda desigual, asimétrica, los roles "del que ayuda" $y$ "del que recibe la ayuda" son fijos en la relación. Los intercambios no son posibles, los actores desempeñan roles que no se pueden cambiar o sustituir a pesar de los deseos. Rosalba califica los intercambios que tiene en el marco de la ayuda mutua con fines domésticos en términos de "caer en una trampa", dado que las condiciones en las que se ofrece la ayuda mutua no son claras; por esta razón, ella terminó realizando actividades de trabajo infantil doméstico. 
La ayuda mutua con fines domésticos entre miembros de familias con vínculo directo se percibe como una ayuda porque no es remunerada, a pesar de que se trate en la práctica de un trabajo, demanda un esfuerzo del menor y de inversiones en término de tiempo e inclusive de dinero. A partir de esta experiencia, Rosalba volverá a preparar nuevamente su traslado a Lima, va buscar un empleo en servicio doméstico fuera de la red familiar, va priorizar más bien sus vínculos sociales y le solicitará ayuda a un amigo. Esta nueva salida es estratégica porque Rosalba identifica los límites entre la ayuda mutua con fines domésticos que encubre el trabajo infantil doméstico entre familiares y el servicio doméstico remunerado.

\section{Conclusiones}

Las características del trabajo infantil doméstico que se desarrolla dentro de las redes familiares son complejas y difíciles de identificar, las experiencias y las trayectorias de los menores son diversas, dependen de los vínculos que tengan los actores, de los compromisos que asuman las familias que reciben a los menores $y$ las familias de los menores. La frontera entre las prácticas de la circulación infantil, de la ayuda mutua con fines domésticos y del trabajo infantil son movibles y poco claras; depende entonces de las interpretaciones que les den los actores a dichas prácticas y de la intensidad de sus vínculos familiares. El parentesco no asegura buenos tratos a los niños que ayudan o trabajan realizando actividades domésticas para un miembro de su familia. La ayuda mutua con fines domésticos parece ser una práctica previa al trabajo infantil doméstico que se realiza en el marco de la ayuda mutua en las redes familiares y es una forma de insertar a los niños en el mundo del trabajo infantil.

Si hace unas décadas, la contratación de menores en el servicio doméstico se realizaba sobre todo a través de prácticas del compadrazgo y padrinazgo o por el enganche a través de redes sociales y familiares; se observa que dichas modalidades de inserción persisten en nuestra sociedad hasta la actualidad, solo que han cambiado en sus formas de captar a los menores. Se tornan entonces menos visibles, dado que la inserción de menores en el trabajo infantil doméstico se da preferentemente dentro de las redes familiares, en un círculo de íntimos, cuando las personas tienen relaciones familiares muy cercanas. La profesionalización del servicio doméstico, la mediatización de casos de abusos y vulnerabilidad de los menores que trabajan en trabajo infantil doméstico, así como la identificación de 
dicha actividad como una de las peores formas de trabajo infantil, no ha contribuido a eliminar esta práctica sino más bien a silenciarla.

\section{Bibliografía}

ALARCÓN, W. (2012). Trabajo infantil en los Andes. Proyecto Solidario por la Infancia. Lima: IEP-Fundación Telefónica.

BIDART, C., DEGENNE, A. et GROSSETTI, M. (2011). La vie en réseaux. Dynamiques des relations sociales. Paris : Presses universitaires de France.

BHUKUTH, A. (2009). Le travail des enfants: limites de la définition. Mondes en développement, 2009/2, N¹46, De Boeck Université, p. 27-32.

BLOMSTER, V. (2004). De la sierra a la capital. Trabajadoras del hogar Lima-Perú. Lima:Asociación Grupo de Trabajo REDES.

CHRISTINAT, J.L. (1989). Des parrains pour la vie. Parenté rituelle dans une communauté des Andes péruviennes. Paris: Éditions de l'Institut d'ethnologie, Neuchâtel - Éditions de la Maison des Sciences de l'homme.

DURIN, S. (Coord.) (2014). Trabajadoras en la sombra. Dimensiones del servicio doméstico latinoamericano. México : CIESAS - La Casa Chata.

EsCALANTE, C. (2002). Estudio sobre el aspecto cultural en el trabajo infantil en Perú. Documento de Proyecto. Lima : OIT.

FONSECA, C. (2000). La circulation des enfants pauvres au Brésil: une pratique locale dans un monde globalisé. Anthropologie et Sociétés, vol. 24, N. 3, p. 53-73.

FONSECA, C. (1985). Valeur marchande, amour maternel et survie: aspects de la circulation des enfants dans une bidonville brésilien, Annales. Économies, Sociétés, civilisations, 40e année, N. ${ }^{\circ}$ 5, p. 991-1022.

INVERNIZZI, A. (2001). La vie quotidienne des enfants travailleurs: stratégies de survie et socialisation dans les rues de Lima. París: L'Harmattan.

JACQUEMIN, M. (2009). « Petites nièces » et « petites bonnes » à Abidjan. Les mutations de la domesticité juvénile. Travail, Genre et Sociétés, 2009/2, N.ํ2ㄹ. p. 53-74.

JACQUEMIN, M. (2007). Sociologie du service domestique juvénile: "petites nièces" et "petites bonnes" à Abidjan, Thèse de doctorat, Paris : EHESS (Études Africaines).

LEINAWEAVER, J. B. (2009). Los niños ayacuchanos. Una antropología de la adopción y de la construcción familiar en el Perú. Lima: Instituto de Estudios Peruanos.

OIT (2013). Erradicar el trabajo infantil en el trabajo doméstico y proteger a los jóvenes contra las condiciones de trabajo abusivas. Ginebra: Publicaciones OIT.

OIT (2008). Encuesta sobre trabajo infantil en el Perú. Lima: Publicaciones OIT. 
OIT (2004). Perfil del trabajo infantil doméstico en Brasil, Colombia, Paraguay y Perú. Contexto, estudios y resultados. Programa IPEC. Lima: Publicaciones OIT.

PETITE, S. (2005). Les règles de l'entraide. Sociologie d'une pratique sociale. Rennes: Presses Universitaires de Rennes.

SANDOVAL, C. (2015). Trabajo infantil doméstico en un contexto de marginalidad urbana en Lima, Perú. Trabajadoras en la sombra. Dimensiones del servicio doméstico latinoamericano. México: CIESAS - La Casa Chata, pp. 111-133. 